\title{
Influence of argan fruit peel on the quality and oxidative stability of argan oil after prolonged storage
}

\author{
Hicham Harhar ${ }^{1 *}$, Said Gharby ${ }^{1,2}$, Dominique Guillaume ${ }^{3}$, Zakia Bouzoubaa ${ }^{4}$, Badr Eddine Kartah, \\ Zoubida Charrouf ${ }^{1}$
}

${ }^{1}$ Laboratoire de Chimie des Plantes et de Synthèse Organique et Bioorganique, Faculté des Sciences, Université Mohammed V, BP 1014Rabat, Morocco; ${ }^{2}$ Etablissement Autonome de Contrôle et de coordination des exportations, Agadir, Morocco; ${ }^{3}$ CNRS-UMR7312, UFR Médecine-Pharmacie, 51 rue Cognacq-Jay, 51100 Reims, France; ${ }^{4}$ INRA-CRRA Agadir- Unité de Recherche Ressources Naturelles et Produits de Terroir, Laboratoire d'Agrophysiologie, B.P. 124, Inezgane, (Maroc)

\section{A B S TR A C T}

The quality of argan oil produced from peeled- or unpeeled-fruit stored for up to two years was investigated. Key physicochemical parameters were periodically determined during the study: peroxide and acid value, specific extinction, fatty acid content, and tocopherol content. Since no significant differences were observed in the composition of argan oil prepared from fruit stored with or without peel over a two-year period, argan fruit peel does not influence the physicochemical properties of argan oil.

Keywords: Edible oil; Cosmetic oil; Peroxide value; Acid value; Specific extinction; Fatty acid; Tocopherol

\section{INTRODUCTION}

The argan tree [Argania spinosa (L.) Skeels], belongs to the Sapotaceae family. This tree that is exclusively endemic to southwestern Morocco where it has had an essential cultural and ecological function for centuries (Ourrach et al., 2012). Nowadays, the argan forest covers over about 320,000 square miles and plays a crucial role in the rural and urban economy (Charrouf and Guillaume, 2009). Argan fruit is coated by a thick peel-covered milky pulp. Once the pulp is dry, peeling argan fruit is easy (Charrouf et al., 2002). It affords argan nuts that contain two or three almonds used to prepare argan oil, an edible and cosmetic oil (Guillaume and Charrouf, 2011; Zaanoun et al., 2014) known to be particularly rich in unsaturated fatty acids and tocopherols (Charrouf and Guillaume, 1999; Harhar et al., 2011; Gharby et al., 2013). In the argan forest, peel-cover ripe argan fruit is collected between July and September (Harhar et al., 2014). The collect is sun-dried and a large part of it is then stored to be processed later, ascertaining an all-year-long production. Fruit peeling can be performed either prior to storage or just prior to fruit processing.
We have recently shown that a 2 -week fruit drying time is optimum to prepare high quality argan oil (Harhar et al., 2010). However, fruit alteration could occur during the storage period that separates fruit drying and fruit processing. Since argan oil is not a refined oil, low fruit-quality would inevitably result in a low-quality oil. Therefore, fruit quality must be ascertained during the total storage period to maintain the high quality commitments of argan oil producers. To our knowledge no study has ever been performed to determine the lifespan of argan fruit in terms of resulting argan oil quality. The aim of this work is to analyze the storage behavior of argan fruit over two years using essential physico-chemical parameters as acid and peroxide value, fatty acid composition or tocopherol content and define if late fruit peeling influences argan oil quality.

\section{MATERIALS AND METHODS}

\section{Material and experimental design}

Argan fruit was collected in Tiout (Taroudant County, Morocco) in August 2007. Collected fruit was sun-dried for two weeks. After this period, half of the collect was

\footnotetext{
*Corresponding author:

Hicham Harhar, Laboratoire de Chimie des Plantes et de Synthèse Organique et Bioorganique, Faculté des Sciences,

Université Mohammed V, BP 1014- Rabat, Morocco. E-mail: hichamoo79@yahoo.fr
} 
mechanically peeled (SMIR Technotour, Agadir, Morocco) and fruit of the second half was stored with its dry peel. For the study, fruit was stored at room temperature over two years in large dark brown cloth bags.

To prepare argan oil, argan kernels from peeled and unpeeled fruit were separately ground, then argan oil was hexane-extracted using a Soxhlet apparatus.

Oil was analyzed just after being extracted and analyses were repeated every 4 months over the 2 years of storage. Duplicate measurements were carried out on each of three replicate samples. All reagents were of analytical or HPLC grade. Iso-octane and iso-propanol, used as HPLC mobile phase, and cyclohexane used for extinction coefficient determination were purchased from Professional Labo (Casablanca, Morocco).

\section{Methods}

Oil yield

Determination of oil yield was performed following the ISO 659 recommendation (ISO 659, 1998). Twenty grams of ground kernels were placed in a Soxhlet apparatus and extracted with $150 \mathrm{~mL}$ of hexane for $8 \mathrm{~h}$. The organic phase was then concentrated under vacuum and dried for $5 \mathrm{~min}$ in an oven at $105^{\circ} \mathrm{C}$. After determination of the extraction yield, the oil was used for the other analyses.

\section{Physicochemical measurements}

Physicochemical parameters

Determination of physicochemical parameters (acidity, peroxide value and UV absorption), was carried out according to the analytical methods described by Regulation EEC/2568/91 of European Union Commission (EC, 2003). Acidity, expressed as percentage of oleic acid, was determined by titration of a solution of oil dissolved in $\mathrm{EtOH} / \mathrm{Et}_{2} \mathrm{O}(1: 1)$ with $0.1 \mathrm{M} \mathrm{KOH}$ in EtOH. To determine the peroxide value, expressed as milli-equivalents of active oxygen per kilogram of oil (meq $/ \mathrm{kg}$ ), a mixture of oil and iso-octane-acetic acid was left to react with a solution of $\mathrm{KI}$ in the darkness; the free iodine was then titrated with a sodium thiosulfate solution.

K270 and K232 extinction coefficients were determined from absorption at $\lambda 270$ and $232 \mathrm{~nm}$, respectively, with a UV spectrophotometer (CARY 100 Varian UV spectrometer), using pure cyclohexane as a blank.

\section{Fatty acid composition}

Oil samples were saponified according to the ISO 5509 standard method (ISO 5509, 2000). Into $5 \mathrm{~mL}$ screw top test tubes, $0.60 \mathrm{~g}$ of oil and $4 \mathrm{ml}$ of iso-octane were introduced, followed by $0.20 \mathrm{~mL}$ of $2 \mathrm{~N}$ methanolic $\mathrm{KOH}$ solution was added. Tubes were tightened with a screw cap provided with a PTEF joint, then vigorously shaken. The upper layer was separated and methyl esters were extracted with hexane. Aliquots $(1 \mu \mathrm{L})$ were injected into a gas chromatograph (Varian CP-3800, Varian Inc.) equipped with a FID. The column used was a CP- Wax 52CB column $(30 \mathrm{~m} \times 0.25 \mathrm{~mm}$ i.d.; Varian Inc., Middelburg, The Netherlands). The carrier gas was helium, and the total gas flow rate was $1 \mathrm{~mL} / \mathrm{min}$. The initial column temperature was $170^{\circ} \mathrm{C}$, the final temperature $230^{\circ} \mathrm{C}$, and the temperature was increased by steps of $4^{\circ} \mathrm{C} / \mathrm{min}$. The injector and detector temperature was $230^{\circ} \mathrm{C}$. Data were processed using Varian Star Workstation v 6.30 (Varian Inc., Walnut Creek, CA, USA).

\section{Tocopherol Content}

Tocopherol was analyzed by HPLC using Shimadzu CR8A instruments (Champ-sur-Marne, France) equipped with a C18-Varian column $(25 \mathrm{~cm} \times 4 \mathrm{~mm}$; Varian Inc., Middelburg, TheNetherlands). A solution of $250 \mathrm{mg}$ of oil in $25 \mathrm{~mL}$ of $\mathrm{n}$-heptane was used. Detection was performed using a fluorescence detector (excitation wavelength $290 \mathrm{~nm}$, detection wavelength $330 \mathrm{~nm}$ ). A mixture of 99:1 isooctane/isopropanol $(\mathrm{V} / \mathrm{V})$ was used as eluent at a flow rate of $1.2 \mathrm{~mL} / \mathrm{min}$.

\section{Statistical analysis}

Values reported in tables are the means \pm SE of 2-3 replications.

\section{RESULTS AND DISCUSSION}

\section{Oil yield}

Satisfactorily, extraction yield of argan oil from peeled- or unpeeled-fruit remained remarkably stable over two years (Table 1). Such stability establishes that when argan fruit is stored in dark cloth bags, these later provide sufficient light protection so the triglyceride content inside argan kernels is sufficiently well protected from external agressions and that the protection is not dependent on the presence of the peel. Since such protection remains efficient for at least two years, in terms of oil yield, argan tree fruit can be stored for two years. With this parameter established, we decided to analyze the quality of the oil over such long storage time.

\section{Peroxide value}

To assess the quality of argan oil, we measured several physico-chemical markers and began with the determination of the peroxide value that depicts the oxidative state of the oil.

Peroxide value remained stable over the first year of storage (Table 1). The slight decrease observed in argan oil produced from peeled- or unpeeled fruit after one year of storage is likely to result of the slow formation of secondary oxidation products within the kernels. After twelve months 
Harhar, et al.: Influence of argan fruit peel on argan oil

Table 1: Oil yield, peroxide (mEq. $\mathrm{O}_{2} / \mathrm{kg}$ ), and acid value (oleic acid equiv.) in argan oil prepared from unpeeled- and peeled fruit stored for up to 2 years

\begin{tabular}{|c|c|c|c|c|c|c|}
\hline \multirow{2}{*}{$\begin{array}{l}\text { Storage time } \\
\text { (month) }\end{array}$} & \multicolumn{3}{|c|}{ Unpeeled fruit } & \multicolumn{3}{|c|}{ Peeled fruit } \\
\hline & Oil yield (\%) & Peroxide value & Acid value & Oil yield (\%) & Peroxide value & Acid value \\
\hline 0 & $55 \pm 1$ & $1.86 \pm 0.15^{\mathrm{a}}$ & $0.20 \pm 0.01^{a}$ & $55 \pm 1$ & $2.00 \pm 0.30^{a}$ & $0.20 \pm 0.01^{a}$ \\
\hline 4 & $54 \pm 1$ & $2.33 \pm 0.10^{\mathrm{a}}$ & $0.22 \pm 0.01^{\mathrm{a}}$ & $53 \pm 1$ & $1.83 \pm 0.25^{\mathrm{a}}$ & $0.20 \pm 0.02^{\mathrm{a}}$ \\
\hline 8 & $55 \pm 1$ & $1.41 \pm 0.08^{b}$ & $0.25 \pm 0.01^{a}$ & $53 \pm 1$ & $2.16 \pm 0.20^{\mathrm{a}}$ & $0.33 \pm 0.01^{b}$ \\
\hline 12 & $54 \pm 1$ & $1.30 \pm 0.10^{b}$ & $0.25 \pm 0.01^{a}$ & $55 \pm 1$ & $1.37 \pm 0.15^{b}$ & $0.40 \pm 0.01^{b}$ \\
\hline 16 & $54 \pm 1$ & $4.60 \pm 0.20^{\circ}$ & $0.23 \pm 0.02^{\mathrm{a}}$ & $55 \pm 1$ & $4.06 \pm 0.15^{c}$ & $0.24 \pm 0.05^{a}$ \\
\hline 20 & $54 \pm 1$ & $4.75 \pm 0.31^{d}$ & $0.21 \pm 0.02^{\mathrm{a}}$ & $54 \pm 1$ & $4.60 \pm 0.10^{d}$ & $0.20 \pm 0.05^{a}$ \\
\hline 24 & $55 \pm 1$ & $6.33 \pm 0.25^{e}$ & $0.51 \pm 0.01^{b}$ & $54 \pm 1$ & $7.11 \pm 0.07^{e}$ & $0.54 \pm 0.03^{c}$ \\
\hline
\end{tabular}

a-e: The values indexed by a different letter within the same column are significantly different at 0.05 significant level

of storage, peroxide value began to significantly increase, reaching after two years 6.33 and $7.11 \mathrm{mEq}$. O2/ $\mathrm{kg}$ for unpeeled- and peeled-fruit, respectively (Table 1). The observed stability of the peroxide value over one year is likely the combined result of the shielding of argan kernels against oxygen by the shell and of the presence of a large amount of antioxidants, as tocopherols, in the kernels (Gharby et al., 2012). Despite the noticeable increase observed during the second half of the storage period, peroxide value of argan oil remained constantly below the $15 \mathrm{mEq}$. O2/ kg, the official limit imposed by the Moroccan official norm to satisfy the extra-virgin regulation (SNIMA, 2003).

\section{Acid value}

Acid value of argan oil prepared from peeled- or unpeeledfruit stored remained remarkably stable over the first 20 months of storage (Table 1). Only after the twentieth month of storage, oil acid value started to significantly increase to reach after 24 months the value of 0.51 and 0.54 for unpeeled-and peeled-fruit derived oil, respectively (Table 1). Therefore triglyceride hydrolysis is wellprevented by the nut-shell and not influenced by the peel presence over 20 months, delay after which ester hydrolysis begins. Nevertheless, even after 2 years of storage, argan oil prepared from both types of fruit still satisfied the standards necessary to be labeled "extra virgin argan oil" according to SNIMA (SNIMA, 2003).

\section{Specific extinction}

Specific extinction can be used to evaluate the presence of primary (K232) or secondary (K270) oxidation products in oils.

Regardless of the storage time and of the presence of a surrounding pulp, the specific extinction at $232 \mathrm{~nm}$ (K232) of argan oil started to undergo a significant increase only after 16 months of kernel storage (Table 2). Such observation is fully in line with peroxide value results (Table 1) that similarly indicated an increase in peroxide formation (primary oxidation products) after 16 months. Therefore, our study indicates that primary oxidation
Table 2: Specific absorption at $\lambda 232$ and $270 \mathrm{~nm}$ and rancimat induction time of argan oil prepared from unpeeled- and peeled fruit stored for up to 2 years

\begin{tabular}{lccccc}
\hline $\begin{array}{l}\text { Storage time } \\
\text { (month) }\end{array}$ & \multicolumn{2}{c}{ Unpeeled fruit } & & \multicolumn{2}{c}{ Peeled fruit } \\
\cline { 2 - 3 } \cline { 5 - 6 } & $\mathbf{K}_{232}$ & $\mathbf{K}_{270}$ & & $\mathbf{K}_{232}$ & $\mathbf{K}_{270}$ \\
\hline & $1.12 \pm 0.01^{\mathrm{a}}$ & $0.14 \pm 0.05^{\mathrm{a}}$ & & $1.11 \pm 0.01^{\mathrm{a}}$ & $0.13 \pm 0.05^{\mathrm{a}}$ \\
8 & $1.13 \pm 0.01^{\mathrm{a}}$ & $0.11 \pm 0.01^{\mathrm{a}}$ & & $1.15 \pm 0.02^{\mathrm{a}}$ & $0.11 \pm 0.01^{\mathrm{a}}$ \\
8 & $1.07 \pm 0.04^{\mathrm{a}}$ & $0.11 \pm 0.01^{\mathrm{a}}$ & & $1.13 \pm 0.01^{\mathrm{a}}$ & $0.13 \pm 0.02^{\mathrm{a}}$ \\
12 & $1.08 \pm 0.01^{\mathrm{a}}$ & $0.14 \pm 0.05^{\mathrm{a}}$ & & $1.16 \pm 0.03^{\mathrm{a}}$ & $0.22 \pm 0.01^{\mathrm{b}}$ \\
16 & $1.22 \pm 0.02^{\mathrm{b}}$ & $0.24 \pm 0.02^{\mathrm{b}}$ & & $1.28 \pm 0.02^{\mathrm{b}}$ & $0.15 \pm 0.05^{\mathrm{a}}$ \\
20 & $1.42 \pm 0.02^{\mathrm{c}}$ & $0.23 \pm 0.05^{\mathrm{b}}$ & & $1.14 \pm 0.02^{\mathrm{a}}$ & $0.28 \pm 0.01^{\mathrm{b}}$ \\
24 & $1.65 \pm 0.01^{\mathrm{d}}$ & $0.29 \pm 0.05^{\mathrm{b}}$ & & $1.41 \pm 0.25^{\mathrm{b}}$ & $0.27 \pm 0.06^{\mathrm{b}}$ \\
\hline
\end{tabular}

a-d: The values indexed by a different letter within the same column are significantly different at 0.05 significant level

products begin to accumulate in argan kernels only after 16 months. Secondary oxidation products derived from primary oxidation products. Accordingly, a slight increase in K270 was detected in argan oil prepared from fruit stored more than 20 months (Table 2). Such increase is hence the results of the degradation of the primary oxidation products observed by K232 analysis. Observed reduced variations in specific absorption at 232 and $270 \mathrm{~nm}$ established that argan oil does not undergo oxidative tranformation whether argan fruit is peeled or not.

\section{Fatty acid composition}

Polyunsaturated fatty acids (PUFAs) are known to be highly sensitive to oxidation. Storage for 24 months of peeled- or unpeeled-fruit had no influence on the fatty acid composition of argan oil. Interestingly, distribution of unsaturated fatty acids (oleic and linoleic acid) whose presence is essential for argan oil properties remained particularly stable (Table 3 ), attesting the high quality of argan oil even after 24 months of storage. Furthermore, all extracted oil samples were found within the SNIMA official norm for extra virgin argan oil (SNIMA, 2003). Argan oil high content in tocopherols, phospholipids, and sterols is likely to be responsible for such stability (Gharby et al., 2012).

\section{Tocopherol composition}

Argan oil is known to be particularly rich in $\gamma$-tocopherol (Gharby et al., 2011). This high content is likely to be 
Harhar, et al.: Influence of argan fruit peel on argan oil

Table 3: Fatty acid percentage in argan oil prepared from unpeeled- and peeled fruit stored for up to 2 years

\begin{tabular}{|c|c|c|c|c|c|c|c|c|}
\hline \multirow{2}{*}{$\begin{array}{l}\text { Storage time } \\
\text { (month) }\end{array}$} & \multicolumn{2}{|c|}{ Oleic acid } & \multicolumn{2}{|c|}{ Linoleic acid } & \multicolumn{2}{|c|}{ Palmitic acid } & \multicolumn{2}{|c|}{ Stearic acid } \\
\hline & Unpeeled & Peeled & Unpeeled & Peeled & Unpeeled & Peeled & Unpeeled & Peeled \\
\hline 0 & \multicolumn{2}{|c|}{$47.3 \pm 0.1$} & \multicolumn{2}{|c|}{$30.1 \pm 0.1$} & \multicolumn{2}{|c|}{$16.3+0.1$} & \multicolumn{2}{|c|}{$5.9+0.1$} \\
\hline 4 & $46.9 \pm 0.1$ & $46.9 \pm 0.1$ & $30.4 \pm 0.1$ & $30.8 \pm 0.1$ & $15.5+0.1$ & $15.3+0.1$ & $5.9+0.1$ & $5.8+0.1$ \\
\hline 8 & $46.3 \pm 0.1$ & $46.3 \pm 0.1$ & $30.7 \pm 0.1$ & $31.3 \pm 0.1$ & $14.3+0.1$ & $14.7+0.1$ & $6.1 \pm 0.1$ & $5.9 \pm 0.1$ \\
\hline 12 & $46.5 \pm 0.1$ & $46.4 \pm 0.1$ & $31.6 \pm 0.1$ & $31.7 \pm 0.1$ & $14.3+0.1$ & $14.6+0.1$ & $6.1 \pm 0.1$ & $5.9 \pm 0.1$ \\
\hline 16 & $47.5 \pm 0.1$ & $47.4 \pm 0.1$ & $31.2 \pm 0.1$ & $31.2 \pm 0.1$ & $14.4+0.1$ & $14.5+0.1$ & $6.1 \pm 0.1$ & $6.1 \pm 0.1$ \\
\hline 20 & $47.6 \pm 0.1$ & $47.8 \pm 0.1$ & $31.2 \pm 0.1$ & $31.3 \pm 0.1$ & $14.2+0.1$ & $13.8+0.1$ & $6.2 \pm 0.1$ & $6.2 \pm 0.1$ \\
\hline \multirow[t]{3}{*}{24} & $47.6 \pm 0.1$ & $47.6 \pm 0.1$ & $31.4 \pm 0.1$ & $31.4 \pm 0.1$ & $14.1+0.1$ & $14.1+0.1$ & $6.1 \pm 0.1$ & $6.3 \pm 0.1$ \\
\hline & \multicolumn{2}{|c|}{ Linolenic acid } & \multicolumn{2}{|c|}{ Total SFA } & \multicolumn{2}{|c|}{ Total MUFA } & \multicolumn{2}{|c|}{ Total PUFA } \\
\hline & Unpeeled & Peeled & Unpeeled & Peeled & Unpeeled & Peeled & Unpeeled & Peeled \\
\hline 0 & \multicolumn{2}{|c|}{$0.3 \pm 0.1$} & \multicolumn{2}{|c|}{$21.2 \pm 0.1$} & \multicolumn{2}{|c|}{$47.5+0.2$} & \multicolumn{2}{|c|}{$31.6+0.2$} \\
\hline 4 & $0.3 \pm 0.1$ & $0.3 \pm 0.1$ & $21.3 \pm 0.1$ & $21.4 \pm 0.1$ & $47.5+0.2$ & $47.2+0.2$ & $31.5+0.2$ & $31.3+0.2$ \\
\hline 8 & $0.3 \pm 0.1$ & $0.3 \pm 0.1$ & $20.9 \pm 0.1$ & $21.1 \pm 0.1$ & $46.9+0.2$ & $46.9+0.2$ & $31.1 \pm 0.2$ & $31.2 \pm 0.2$ \\
\hline 12 & $0.3 \pm 0.1$ & $0.2 \pm 0.1$ & $20.9 \pm 0.1$ & $20.7 \pm 0.1$ & $46.9+0.2$ & $46.8+0.2$ & $31.6 \pm 0.2$ & $31.3 \pm 0.2$ \\
\hline 16 & $0.2 \pm 0.1$ & $0.2 \pm 0.1$ & $20.7 \pm 0.1$ & $20.8 \pm 0.1$ & $47.7+0.2$ & $47.6+0.2$ & $31.6 \pm 0.2$ & $31.6 \pm 0.2$ \\
\hline 20 & $0.3 \pm 0.1$ & $0.2 \pm 0.1$ & $20.9 \pm 0.1$ & $20.8 \pm 0.1$ & $47.8+0.2$ & $48.0+0.2$ & $31.7 \pm 0.2$ & $31.7 \pm 0.2$ \\
\hline 24 & $0.3 \pm 0.1$ & $0.2 \pm 0.1$ & $21.5 \pm 0.1$ & $21.1 \pm 0.1$ & $47.8+0.2$ & $47.8+0.2$ & $30.8 \pm 0.2$ & $31.1 \pm 0.2$ \\
\hline
\end{tabular}

SFA: Saturated fatty acid, MUFA: Monounsaturated fatty acid, PUFA: Polyunsaturated fatty acid

Table 4: Tocopherol content $(\mathrm{mg} / \mathrm{kg})$ in argan oil prepared from unpeeled- and peeled fruit stored for up to 2 years

\begin{tabular}{|c|c|c|c|c|c|c|c|c|}
\hline \multirow{2}{*}{$\begin{array}{l}\text { Storage time } \\
\text { (month) }\end{array}$} & \multicolumn{2}{|c|}{$\alpha$-Tocopherol } & \multicolumn{2}{|c|}{$\beta$-Tocopherol } & \multicolumn{2}{|c|}{$\gamma$-Tocopherol } & \multicolumn{2}{|c|}{$\delta$-Tocopherol } \\
\hline & Unpeeled & Peeled & Unpeeled & Peeled & Unpeeled & Peeled & Unpeeled & Peeled \\
\hline 0 & \multicolumn{2}{|c|}{$65 \pm 8$} & \multicolumn{2}{|c|}{$7 \pm 0.5$} & \multicolumn{2}{|c|}{$550 \pm 19$} & \multicolumn{2}{|c|}{$55 \pm 2$} \\
\hline 4 & $65 \pm 3$ & $68 \pm 5$ & $8 \pm 1$ & $9 \pm 2$ & $560 \pm 13$ & $563 \pm 10$ & $57 \pm 4$ & $58 \pm 2$ \\
\hline 8 & $64 \pm 2$ & $63 \pm 2$ & $7 \pm 2$ & $7 \pm 2$ & $553 \pm 8$ & $559 \pm 12$ & $54 \pm 1$ & $55 \pm 4$ \\
\hline 20 & $60 \pm 5$ & $62 \pm 5$ & $4 \pm 3$ & $3 \pm 3$ & $539 \pm 15$ & $545 \pm 14$ & $53 \pm 3$ & $54 \pm 2$ \\
\hline 24 & $55 \pm 3$ & $52 \pm 3$ & - & - & $530 \pm 11$ & $525 \pm 8$ & $53 \pm 2$ & $52 \pm 2$ \\
\hline
\end{tabular}

responsible of argan oil excellent preservation properties as well as of most of its physiological properties (Guillaume and Charrouf, 2011). Similar tocopherol levels were determined in argan oil prepared from peeled- or unpeeledfruit all over the study (Table 4). Even after 24 months of storage, $\gamma$-tocopherol content in argan oil was found to be very high (Table 4). After the same period of time, $\beta$-tocopherol, the minor tocopherol in argan oil, was found to be below the detection level and $\alpha$-tocopherol level decreased slightly. However, our results show that tocopherol content in argan oil is not sensitive to fruit storage, over two years, and not affected by the presence of the fruit pulp.

\section{CONCLUSION}

Our results unambiguously establish that the storage for 24 months of dried argan-fruit (unpeeled fruit) or argannuts (peeled fruit) does not affect the final quality of the extracted oil. After 2 years of storage, argan kernels coming from unpeeled or peeled fruit still deliver an oil that easily satisfies the Moroccan norm. Therefore, there is no need to envisionne recommendations regarding the storage of argan fruit under a peeled or unpeeled form.

\section{ACKNOWLEDGMENTS}

We thank M. Chafchaouni (Association Ibn Al-Baytar) and the women of the Taitmatine cooperative in Tiout. This work was realized in the frame of "Projet Arganier" supported by "Agence de Développement Social, Maroc" and the EEC.

\section{Author contributions}

H. H., S. G.: made a major contribution to the review paper. D. G. Z. C.: were involved in overall planning and supervision. Z. B. helped in the first phase (collecting and storing fruits), and sent the samples from Tiout (Taroudant) to Rabat every 4 months during 24 months. B. E. K. did extraction of the oil every 4 month during 24 months.

\section{REFERENCES}

Charrouf, Z. and D. Guillaume. 1999. Ethnoeconomical, ethnomedical, and phytochemical study of Argania spinosa (L.) Skeels. J. Ethnopharmacol. 67: 7-14.

Charrouf, Z. and D. Guillaume. 2009. Sustainable development in Northern Africa: The argan forest case. Sustainability. 1: 10121022.

Charrouf, Z., D. Guillaume and A. Driouich. 2002. The argan tree. An 
asset for Morocco. Biofuture. 220: 54-57. In French.

Gharby, S., H. Harhar, D. Guillaume, A. Haddad, B. Matthäus and Z. Charrouf. 2011. Oxidative stability of edible argan oil: A two year study. LWT - Food Sci. Technol. 44: 1-8.

Gharby, S., H. Harhar, D. Guillaume, A. Haddad and Z. Charrouf. 2012. The origin ofvirgin argan oil's high oxidative stability unraveled. Nat. Prod. Commun. 7: 621-624.

Gharby, S., H. Harhar, B. E. Kartah, H. El. Monfalouti, C. Denhez, M. Hilali, D. Guillaume and Z. Charrouf. 2013. Can fruit-form be a marker for argan oil production? Nat. Prod. Commun. 8: 25-28.

Charrouf, Z. and D. Guillaume. 2011. Argan oil. Monograph. Altern. Med. Rev. 16: 275-278.

Harhar, H., S. Gharby, B. E. Kartah, H. El. Monfalouti, Z. Charrouf and D. Guillaume. 2010. Long argan fruit drying time is detrimental for argan oil quality. Nat. Prod. Commun. 5: 1799-1802.

Harhar, H., S. Gharby, B. Kartah, H. El. Monfalouti, D. Guillaume and Z. Charrouf. 2011. Influence of argan kernel roasting-time on virgin argan oil composition and oxidative stability. Plant Foods Hum. Nutr. 66: 163-168.

Harhar, H., S. Gharby, B. Kartah, D. Pioch, D. Guillaume and Z.
Charrouf. 2014. Changes in physical and chemical properties during argan (Argania spinosa L.) Fruit maturation. Ind. Crops Prod. 56: 156-159.

ISO 659. 1998. Oilseeds-Determination of Oil Content (Reference Method)-EN. ISO 659: 1998.

$E C / 2568 / 91$. 2003. Commission of the European communities. Regulation 2568/91 on the characteristics of olive oil and oilveresidue oil and on relevant methods of analysis. Off. J. Eur. Commun. 248: 1-109.

ISO. 5509. 2000. Animal and vegetable fats and oils-preparation of methyl esters of fatty acids.

Ourrach, I., M. Rada, M. C. Pérez-Camino, M. Benaissa and Á. Guinda. 2012. Detection of argan oil adulterated with vegetable oils: New markers. Grasas Aceites. 63(4): 355-364.

SNIMA. 2003. Service de Normalisation Industrielle Marocaine. Huiles d'argane. Spécifications. Norme marocaine NM 08.5.090. Rabat: SNIMA.

Zaanoun, I., S. Gharby, I. Bakass, E. Aitaddi and I. Aitichou. 2014. Kinetic parameter determination of roasted and unroasted argan oil oxidation under rancimat test conditions. Grasas Aceites. 65(3): e033. 